\title{
ANÁLISE DO CONTROLE DE QUALIDADE NA EXECUÇÃO DE ESTRUTURAS DE CONCRETO ARMADO
}

\author{
MARTINS PERDIGÃO, KAROLINE \\ Aluna de graduação \\ Universidade do Estado de Minas Gerais \\ Minas Gerais; Brasil \\ kmartinsperdigao@gmail.com
}

\author{
SOARES CANGUSSÚ, DIANA DARLEN \\ Engenheira Civil/Professora \\ Universidade do Estado de Minas Gerais \\ Minas Gerais; Brasil \\ darlencangussu@gmail.com
}

\author{
SANTOS DOHLER, PHELLIPE \\ Engenheiro Civil \\ Resist Engenharia e Projetos \\ Minas Gerais; Brasil \\ phellipedohler@hotmail.com
}

\section{RESUMO}

O concreto é um material de relevância para a engenharia civil e que desempenha sua função de forma satisfatória quando é produzido, lançado e adensado adequadamente. O processo construtivo e os materiais a ele aplicados tem influência na qualidade e vida útil de um elemento de concreto armado. A pesquisa tem por objetivo identificar e diagnosticar falhas relativas às deficiências de controle de qualidade na etapa construtiva de execução de estruturas de concreto armado, por meio de análise de ocorrências de manifestações patológicas encontradas em uma edificação residencial multifamiliar com quatro pavimentos, em Teófilo Otoni/MG e posteriores procedimentos de recuperação. Foi desenvolvido um método de pesquisa baseado no estudo de caso da edificação, com realização de vistorias, utilizando inspeção preliminar, inspeção detalhada e diagnóstico. Conclui-se que, com os resultados da análise, as manifestações patológicas apresentadas tiveram origem na ineficiência de execução das estruturas de concreto armado, sendo necessário um controle adequado dos processos e materiais empregados na construção.

Palavras-chave: concreto armado, construção civil, manifestação patológica, qualidade, vida útil.

\section{ABSTRACT}

Concrete is a material of relevance for civil engineering and that performs its function satisfactorily when it is produced, launched and densified properly. The construction process and the materials applied to it have an influence on the quality and useful life of a reinforced concrete element. The research aims to identify and diagnose failures related to deficiencies in quality control in the constructive stage of execution of reinforced concrete structures, through the analysis of occurrences of pathological manifestations found in a multifamily residential building with four floors, in Teofilo Otoni/MG and subsequent recovery procedures. A research method was developed based on the case study of the building, with surveys, using preliminary inspection, detailed inspection and diagnosis. It is concluded that, with the results of the analyze, the pathological manifestations presented originated in the inefficiency of execution of the reinforced concrete structures, being necessary an adequate control of the processes and materials used in the construction.

Keywords: reinforced concrete, civil construction, pathological manifestation, qualit, useful life.

\section{INTRODUÇÃO}

A vida útil (VU) de uma edificação associa-se com a qualidade dos materiais empregados e com os métodos utilizados durante a sua construção. As estruturas de concreto armado devem ser projetadas de acordo com o que estabelece a NBR 6118 (ABNT, 2014) e executadas com base em projetos de estruturas, em atendimento a NBR 14931 (ABNT, 2004), apresentando estabilidade, segurança e aptidão em serviço durante o prazo correspondente à sua VU.

Avaliar o concreto produzido e utilizado em uma obra permite minimizar riscos, prejuízos e manifestações patológicas que afetam a durabilidade, desempenho e estética da edificação em que está sendo aplicado. Na pesquisa de Cupertino 
(2013), que analisou a origem das manifestações patológicas a partir de dados de assistência técnica de edificações residenciais, percebeu-se que cerca de $44 \%$ são provenientes da etapa de execução das obras e $22 \%$ são atribuídas aos materiais.

Esses tipos de falhas ocorrem principalmente pela falta de planejamento na execução, o que compromete o desempenho da estrutura não apenas quanto à durabilidade, mas também na resistência aos esforços para os quais ela foi dimensionada.

A NBR 12655 (ABNT, 2015) dispõe-se das etapas de elaboração do concreto, de forma que a proporção dos materiais atenda à dosagem especificada. Para o recebimento e a aceitação do concreto, a referida norma estabelece os ensaios de consistência e de resistência à compressão para o controle de qualidade.

O objetivo desta pesquisa é identificar e diagnosticar falhas relativas às deficiências de controle de qualidade na etapa construtiva de execução de estruturas de concreto armado, por meio de análise de ocorrências de manifestações patológicas encontradas em uma edificação em Teófilo Otoni/MG, com posteriores procedimentos de recuperação.

\section{QUALIDADE NA EXECUÇÃO DE ESTRUTURAS DE CONCRETO ARMADO}

A qualidade das obras de concreto armado é aferida pelo atendimento aos requisitos de segurança, desempenho e durabilidade. No entanto, atualmente não é raro se ver obras recém-entregues com manifestações patológicas, podendo afetar sua VU. Em diversas vezes, esses problemas poderiam ter sido evitados se todas as medidas necessárias na execução tivessem sido tomadas pelo construtor (PEDROSO, 2018).

O projeto estrutural deve ser realizado por engenheiro civil responsável técnico (engenheiro estrutural), com especificações detalhadas e completas, garantindo que o produto final atenda aos requisitos de segurança, estabilidade e aptidão em serviço durante o período correspondente à sua vida útil de projeto (VUP) previamente estabelecida (ABNT, 2015). Na execução de estruturas de concreto armado é necessário um planejamento e logo após deve ser submetido ao controle da qualidade (conjunto de técnicas operacionais), atuando em todas as etapas do processo construtivo.

\subsection{Requisitos e condições de durabilidade}

O estudo da durabilidade das estruturas de concreto armado evolui devido a um maior conhecimento do seu comportamento, possibilitando a avaliação da VU. Para a NBR 6118 (ABNT, 2014), no item 5.1.2.3, durabilidade consiste na capacidade da estrutura resistir às influências ambientais previstas e definidas pelo engenheiro estrutural e o contratante, no início da elaboração do projeto estrutural, enquanto que a NBR 15575-1 (ABNT, 2013) define durabilidade como a capacidade da edificação ou de seus sistemas de desempenhar suas funções, ao longo do tempo e sob condições de uso e manutenção especificadas.

\subsubsection{Vida útil de projeto}

Dentre os aspectos que interferem no ciclo de vida das construções, destaca-se não apenas a qualidade dos materiais, a plena execução das técnicas construtivas e as interferências do meio externo, mas também o cálculo da VUP e a realização de manutenções periódicas preventivas ou corretivas, que são responsáveis por conservar ou recuperar o desempenho da estrutura e dos elementos construtivos que integram os edifícios (TUTIKIAN; PACHECO, 2013).

A NBR 6118 (ABNT, 2014) define VUP como o período de tempo durante o qual se mantêm as características das estruturas de concreto, desde que atendidos os requisitos de uso e manutenção prescritos pelo engenheiro estrutural e pelo construtor, bem como de execução dos reparos necessários decorrentes de danos acidentais.

Para a NBR 15575-1 (ABNT, 2013), VUP é o período estimado de tempo para o qual um sistema é projetado, a fim de atender aos requisitos de desempenho, considerando o atendimento às normas NBR 6118 (ABNT, 2014) e NBR 155752 (ABNT, 2013), o estágio do conhecimento durante a elaboração do projeto estrutural e supondo o cumprimento da periodicidade e correta execução dos processos de manutenção especificados no manual de uso, operação e manutenção. 
As estruturas de concreto armado devem ser projetadas e construídas de modo que, sob as condições ambientais previstas no projeto estrutural e quando utilizadas conforme o mesmo projeto, apresentem segurança, estabilidade e aptidão em serviço durante o período correspondente à sua VUP (ABNT, 2015).

\subsubsection{Agressividade ambiental}

A agressividade ambiental está relacionada às ações físicas e químicas que atuam sobre os elementos de concreto armado, independentemente das ações mecânicas, das variações volumétricas de origem térmica, da retração hidráulica e outras previstas no dimensionamento das estruturas de concreto.

A classificação da agressividade ambiental, com base nas condições de exposição da estrutura ou suas partes, deve levar em conta o microclima, no interior e exterior das edificações, e o macroclima, em obras em região rural, urbana, marinha, industrial, com respingos de maré e submersa $\geq 3 \mathrm{~m}$, atuantes sobre a obra e suas partes críticas.

De acordo com a NBR 6118 (ABNT, 2014), a agressividade ambiental é classificada de acordo com o apresentado na Tabela 1 nos projetos estruturais de estruturas de concreto.

Tabela 1 - Classes de agressividade ambiental

\begin{tabular}{c|c|c}
\hline Classe de agressividade ambiental & Agressividade & Risco de deterioração da estrutura \\
\hline I & Fraca & Insignificante \\
\hline II & Moderada & Pequeno \\
\hline III & Forte & Grande \\
\hline IV & Muito forte & Elevado \\
\hline
\end{tabular}

Fonte: ABNT (2014).

\subsection{Controle de qualidade do concreto}

O concreto a ser colocado em uma estrutura deve atender aos critérios de controle da qualidade previstos na NBR 12655 (ABNT, 2015). Para recebimento e aceitação do concreto a referida norma estabelece a realização de dois ensaios de controle.

\subsubsection{Ensaio de consistência}

A NBR NM 67 (ABNT, 1998) especifica o ensaio para determinar a consistência do concreto fresco através da medida de seu assentamento, em laboratório e obra. Nesse ensaio, que determina a facilidade e a homogeneidade com a qual o material pode ser misturado, lançado, adensado e acabado, é feito o preenchimento de um tronco de cone em três camadas de igual altura, sendo cada camada golpeada 25 vezes com uma haste.

O valor do abatimento é a medida do assentamento do concreto logo após a retirada do molde de tronco de cone (ABNT, 1998).

Conforme a NBR 12655 (ABNT, 2015), os ensaios de consistência devem ser realizados:

a) concreto preparado pelo construtor da obra:

- sempre que ocorrerem alterações na umidade dos agregados;

- na primeira amassada do dia;

- ao reiniciar o preparo após uma interrupção da jornada de concretagem de pelo menos 2 h;

- na troca dos operadores;

- cada vez que forem moldados corpos de prova.

b) Concreto dosado em central: o procedimento é repetido a cada betonada que chega à obra.

\subsubsection{Ensaios de resistência à compressão}

Para o ensaio de resistência à compressão, a amostragem do concreto deve ser feita dividindo-se a estrutura em lotes que atendam aos limites estabelecidos pela NBR 12655 (ABNT, 2015), na qual, cada lote deve ser retirada uma amostra, com número de exemplares de acordo com o tipo de controle feito pelo construtor. Os lotes de concreto só devem ser aceitos, quando o valor estimado da resistência característica à compressão do concreto ( $\left.f_{\text {ck,est }}\right)$ satisfizer a relação: 


$$
f_{\text {ck,est }} \geq f_{\text {ck }}(1)
$$

"A resistência à compressão é uma propriedade muito sensível, capaz de indicar com presteza as eventuais variações da qualidade de um concreto, da dosagem ou de seus insumos." (PACHECO; HELENE, 2013).

\subsubsection{Concretagem}

Na concretagem é importante a presença do construtor na etapa de lançamento do concreto, pois a reparação devido o erro na execução é onerosa e pode esconder defeitos que aparecerão somente algum tempo depois.

De acordo a NBR 14931 (ABNT, 2004), para o concreto destinado às estruturas são previstas duas modalidades diferentes de preparo: o concreto preparado pelo executante da obra (construtor) e o concreto preparado por empresa de serviços de concretagem, cumprindo as prescrições da NBR 12655 (ABNT, 2015), bem como as disposições da NBR 7212 (ABNT, 2012).

Dos cuidados preliminares, a NBR 14931 (ABNT, 2004) dispõe das especificações a serem conferidas nas formas antes do lançamento do concreto, para que a estrutura de concreto armado esteja conforme o estabelecido no projeto estrutural. O item 9.2.2 considera que antes do lançamento do concreto devem ser devidamente conferidas as posições e condições estruturais do escoramento, a fim de assegurar que as dimensões e posições das formas sejam mantidas de acordo com o projeto estrutural e permitir o tráfego de pessoal e equipamento necessários à operação de concretagem com segurança.

O plano de concretagem do lançamento deve ser bem elaborado e assegurar o fornecimento da quantidade adequada de concreto com as características necessárias à estrutura, e com uma equipe de operários suficiente para garantir que as operações de lançamento, adensamento e acabamento do concreto sejam realizadas a contento.

Durante o processo de endurecimento o concreto deve ser protegido contra agentes químicos, vibração e choques e curado com a utilização de água. A retirada das formas e do escoramento só pode ser feita quando o concreto estiver suficientemente endurecido, de maneira a não comprometer a segurança e o desempenho em serviço da estrutura.

\subsubsection{Qualidade do concreto de cobrimento}

A durabilidade dos elementos de concreto armado depende das características do concreto, espessura e qualidade do concreto do cobrimento da armadura (ABNT, 2014; ALEXANDER, 2018), que estabelece que o cobrimento mínimo ( $\left.c_{\text {mín }}\right)$ da armadura é o menor valor que deve ser considerado ao longo de todo o elemento de concreto armado, sendo suscetível às influências de deterioração de uma cura insuficiente, secagem em idade precoce, compactação inadequada e a penetração de agentes ambientais agressivos (ALEXANDER, 2018).

O problema da durabilidade em elementos de concreto armado depende em grande parte da qualidade do concreto e da espessura da sua camada de cobrimento, que é função de uma decisão do projeto estrutural e um correto procedimento de execução (ALEXANDER, 2018).

Para garantir o $c_{m i ́ n}$, o projeto estrutural e a execução dos elementos de concreto armado devem considerar o cobrimento nominal $\left(\mathrm{c}_{\text {nom }}\right)$, que é:

$$
\mathrm{c}_{\text {nom }}=\mathrm{c}_{\mathrm{mín}}+\Delta \mathrm{c}(2) \text {. }
$$

Assim, as dimensões das armaduras e os espaçadores devem respeitar os $\mathrm{c}_{\text {nom, }}$, estabelecidos na Tabela 2, para tolerância de execução $\Delta \mathrm{c}=10 \mathrm{~mm}$, devendo ser o valor mínimo para obras correntes.

\begin{tabular}{|c|c|c|c|c|}
\hline \multirow{3}{*}{ Componente ou elemento } & \multicolumn{4}{|c|}{ Classe de agressividade ambiental } \\
\hline & $\mathrm{I}$ & II & III & IV \\
\hline & \multicolumn{4}{|c|}{ Cobrimento nominal (mm) } \\
\hline Laje & 20 & 25 & 35 & 45 \\
\hline Viga/pilar & 25 & 30 & 40 & 50 \\
\hline Elementos de concreto armado em contato com o solo & \multicolumn{2}{|c|}{30} & 40 & 50 \\
\hline
\end{tabular}

Tabela 2 - Classes de agressividade ambiental e cobrimento nominal para $\Delta \mathrm{c}=10 \mathrm{~mm}$

Fonte: ABNT (2014). 
$\mathrm{O}_{\mathrm{nom}}$ está sempre referido à superfície da armadura externa, em geral à face externa do estribo, devendo ser sempre:

$$
\mathrm{c}_{\text {nom }} \phi \geq_{\text {barra }}(3)
$$

A dimensão máxima característica (DMC) do agregado graúdo utilizado no concreto não pode superar em $20 \%$ a espessura nominal do cobrimento, ou seja:

$$
\mathrm{DMC} \leq 1,2 \mathrm{c}_{\text {nom }}(4)
$$

\subsubsection{Armadura longitudinal}

Nas condições de execução da obra, a DMC do agregado graúdo é condicionada à NBR 6118 (ABNT, 2014), quanto à distribuição transversal da armadura longitudinal, pelas dimensões dos elementos estruturais.

Conforme ilustrado na Figura 1, o espaçamento mínimo livre entre as faces das barras longitudinais, medido no plano da seção transversal, deve ser igual ou superior ao maior dos seguintes valores:

a) na direção horizontal $\left(\mathrm{a}_{\mathrm{h}}\right)$ :

$-20 \mathrm{~mm}$;

- diâmetro da barra, do feixe ou da luva;

- 1,2 vez a DMC do agregado graúdo.

b) na direção vertical $\left(\mathrm{a}_{\mathrm{v}}\right)$ :

- $20 \mathrm{~mm}$;

- diâmetro da barra, do feixe ou da luva;

- 0,5 vez a DMC do agregado graúdo.

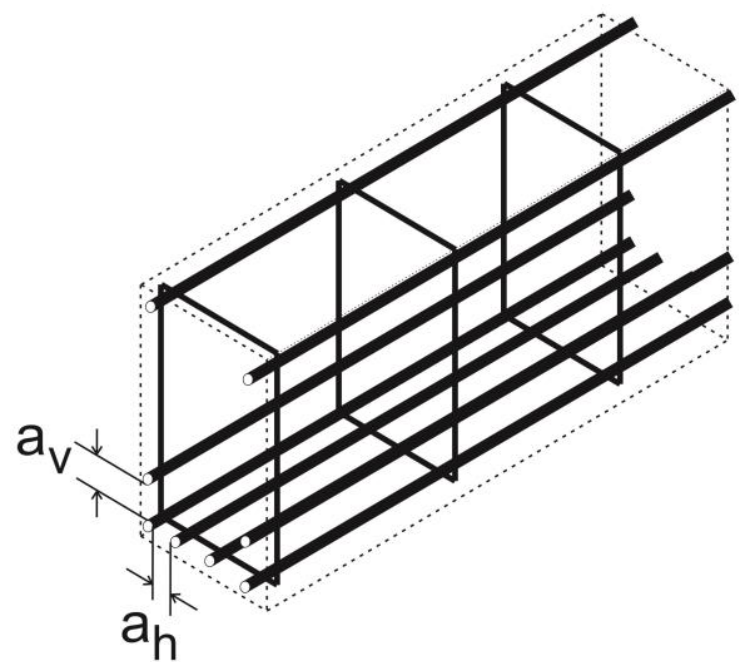

Figura 1: Espaçamento entre as barras longitudinais

A NBR 6118 (ABNT, 2014) determina que o arranjo das armaduras deve atender não só à sua função estrutural, como também às condições adequadas de execução, particularmente com relação ao lançamento e adensamento do concreto e que os espaços devem ser projetados para a introdução do vibrador, de modo a impedir a segregação dos agregados e a ocorrência de vazios no interior do elemento de concreto armado.

A DMC do agregado graúdo também é condicionada pelas dimensões dos elementos estruturais, devendo ser, conforme Rodrigues (1998) e ABNT (2014):

a) menor que $1 / 4$ da menor distância entre as faces da forma;

b) menor que $1 / 3$ da altura das lajes.

\subsection{Deficiências na execução de estruturas de concreto armado}

Os erros de execução de obra são, na maioria das vezes, gerados pela ganância, desconhecimentos e negligência de alguns construtores, pois economizam na elaboração e desenvolvimento dos projetos, que afetam a execução da obra (MARCELLI, 2007). 
A execução de uma estrutura segue uma sequência lógica do processo construtivo, indicando que a etapa de execução deve ser iniciada após o término da etapa de elaboração de todos os projetos (SOUZA; RIPPER, 1998).

As atividades desenvolvidas durante a execução de estruturas de concreto armado podem apresentar:

a) deficiência no cálculo do projeto estrutural;

b) diferença entre a lista de quantidade de armaduras e a planta de armação;

c) projetos estruturais inadequados;

d) realização ineficiente de sondagem;

e) falha nas armaduras, incluindo o cobrimento, a armação, os espaçamentos, as emendas e as ancoragens;

f) falhas na concretagem, envolvendo formas, juntas de dilatação, lançamento e cura do concreto e desformas.

\section{MÉTODO DE PESQUISA}

O método de pesquisa baseou-se no estudo de caso e consistiu de inspeção preliminar e inspeção detalhada, conforme ABECE (2005), a fim de identificar e diagnosticar falhas relativas às deficiências de controle de qualidade na etapa de execução de estruturas de concreto armado, por meio de um estudo de ocorrências de manifestações patológicas encontradas no objeto de estudo e posteriores procedimentos de recuperação, no ano de sua construção, em 2013.

\subsection{Objeto de estudo}

O objeto de estudo consistiu em um edifício residencial multifamiliar, com quatro pavimentos, de médio porte, ilustrado na Figura 2, localizado na cidade de Teófilo Otoni/MG, na região urbana que pode ser inserida na classe de agressividade II da ABNT NBR 12655:2015.

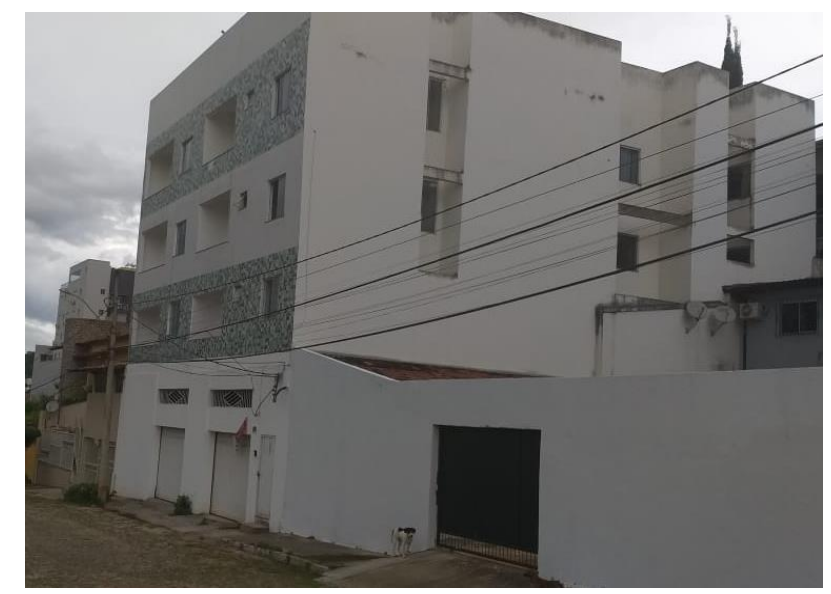

Figura 2: Edifício residencial multifamiliar

\subsection{Inspeção preliminar}

$\mathrm{Na}$ inspeção preliminar fez-se o reconhecimento do objeto de estudo, em que inicialmente foi realizado um levantamento dos projetos arquitetônico e estrutural do edifício e, após, encaminhado um formulário ao profissional responsável técnico pela execução da etapa construtiva de revestimento, a qual a empresa construtora foi contratada.

Procurou-se identificar a natureza e possíveis causas das manifestações patológicas, com coleta de informações prévias através da primeira vistoria na edificação, por meio de exame visual em que foram observadas possíveis manifestações patológicas, com registros fotográficos. Também averiguou-se o meio ambiente em que a edificação se encontrava inserida, com identificação da agressividade ambiental; identificação da espessura do cobrimento do concreto e redução do diâmetro das armaduras.

\subsection{Inspeção detalhada}

A inspeção detalhada ocorreu na segunda visita à edificação, com revisão das manifestações patológicas críticas identificadas na inspeção preliminar e análise em novos locais.

Foi por meio das condições de exposição que foi selecionada a forma de investigação dessas manifestações, em que puderam ser investigadas utilizando procedimentos de visualização. 
A inspeção detalhada pode ser realizada como passo prévio a uma intervenção ou simultaneamente a ela, porém pode não ser necessária a sua realização em certas ocasiões (ANDRADE, 1992).

Após a primeira vistoria na edificação, concluiu-se que não havia necessidade da realização de ensaios, pois por meio da formulação das hipóteses sobre as causas dos problemas encontrados puderam-se buscar evidências que comprovassem essas hipóteses para realizar o diagnóstico.

\subsection{Diagnóstico}

Na etapa diagnóstico todos os dados coletados na inspeção preliminar e detalhada foram interpretados para a definição das prováveis causas, origens e mecanismos das manifestações patológicas, obtendo desta forma, o diagnóstico das mesmas, as quais foram originadas a partir dos tipos de materiais usados, projetos inadequados ou inexistentes e execução com profissionais sem capacitação.

O diagnóstico foi elaborado em forma de relatório técnico, com a descrição das manifestações patológicas encontradas, alternativa de recuperação e com apresentação do prognóstico, indicando o que deve ocorrer no caso da não realização de intervenção e, posteriormente, entregue ao proprietário da edificação.

\section{RESULTADOS E DISCUSSÕES}

Através das inspeções preliminar e detalhada, foram diagnosticadas manifestações patológicas em diversos locais da edificação, com posteriores análises.

\subsection{Segregação do concreto}

A segregação do concreto ocorre devido a uma mistura não homogênea dos seus componentes, resultando em um material não uniforme e não coeso. Também pode-se considerar que se uma nova quantidade de concreto é lançada sobre uma superfície que já completou o processo de endurecimento, pode acontecer a segregação dos seus componentes (SOUZA; RIPPER, 1998).

Este problema originou ao mesmo tempo e decorrente de falhas durante a execução, nas formas e dosagem do concreto.

Para diagnosticar a segregação do concreto foi necessário avaliar o estado que ela se encontrava, podendo ocorrer de três maneiras:

a) superficial: quando há falhas na argamassa da mistura do concreto, em que não há o aparecimento dos agregados graúdos;

b) média: houve grandes falhas na superfície do concreto, com o aparecimento dos agregados graúdos (Figura 3-A);

c) profunda: apresentou profundas imperfeições na superfície do concreto, como parte do agregado graúdo se soltando, muitos vazios e o aparecimento da armadura, conforme a Figura 3-B.

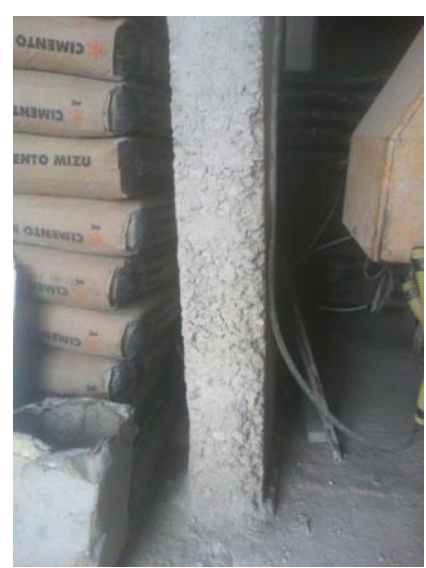

(A)

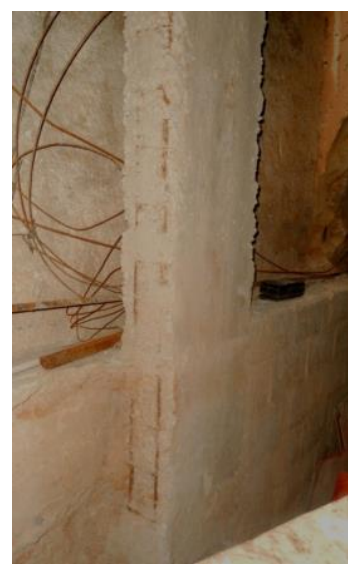

(B)

Figura 3: Segregação nos pilares do pavimento térreo 
Como procedimento para recuperação da segregação do concreto foi realizado:

a) apicoamento para retirar os pedaços de concretos soltos;

b) limpeza da superfície com jatos de água fria e areia;

c) uso manual por escova de aço nas armaduras expostas, no caso da Figura 3-B;

d) aplicação de selador à base de epóxi nas armaduras expostas, no caso da Figura 3-B;

e) aplicação de concreto de alta resistência misturado com aditivo para ajudar na aderência com o concreto mais velho.

A lavagem pela aplicação de jatos de água fria sob pressão controlada é largamente utilizada como técnica de limpeza e preparação do substrato para a futura recepção do material de recuperação. Normalmente, os jatos de água fria muitas vezes são utilizados simultaneamente com os jatos de areia (SOUZA; RIPPER, 1998).

De acordo com o Instituto Brasileiro do Concreto (2015), o congestionamento de barras dificulta a moldagem, propicia a segregação dos componentes do concreto e impede um bom adensamento ao dificultar a entrada do vibrador, comprometendo a capacidade final do concreto endurecido.

Segundo Marcelli (2007), apesar da importância mostrada com relação à vibração do concreto, o excesso pode ser pior do que a falta de vibração, pois pode provocar uma segregação dos agregados e afloramento superficial da água de hidratação do cimento Portland.

\subsection{Nicho de concretagem}

Os nichos de concretagem foram gerados a partir de falhas da concretagem, no adensamento e vibração incorretos do concreto, falha no dimensionamento do $\mathrm{c}_{\text {nom, }}$ relação água/cimento e falta de trabalhabilidade do concreto, conforme ilustra a Figura 4.

Para o tratamento dos nichos de concretagem sem o aparecimento da armadura (Figura 4) foi utilizado o método de limpeza através de jato de água fria e areia para a retirada de impurezas e pequenos pedaços de concreto. Em seguida foi feita uma pintura de zarcão à base de primer de zinco e o enchimento com uma mistura de concreto à base de epóxi.

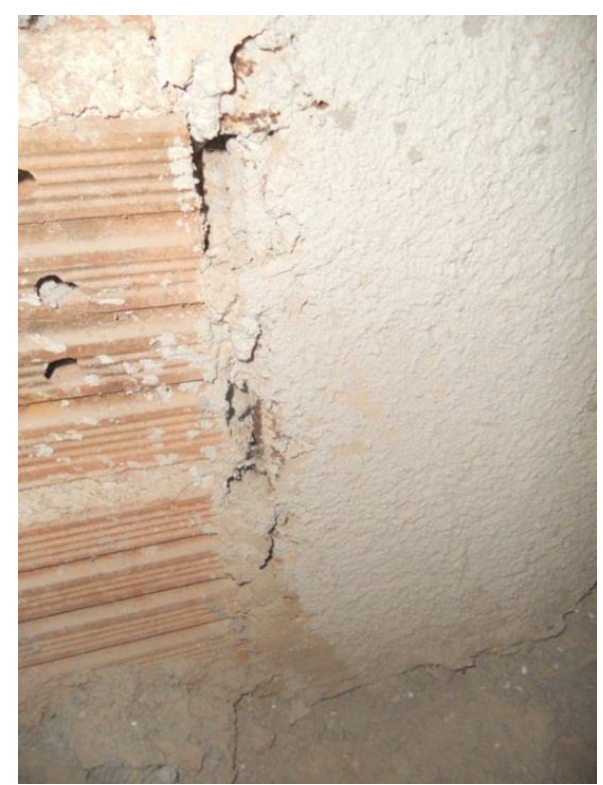

Figura 4: Nicho de concretagem em pilar

No caso do nicho de concretagem em vigas (Figura 5), em que havia o aparecimento da armadura foi utilizado o processo de lixamento das armaduras para a retirada das impurezas e oxidações.

A presença dessas falhas em estruturas de concreto pode causar a corrosão das armaduras, comprometer a estabilidade da estrutura, expondo a agentes agressivos, logo há a perda de resistência aos esforços solicitantes ao longo do tempo, podendo chegar ao colapso da estrutura. 


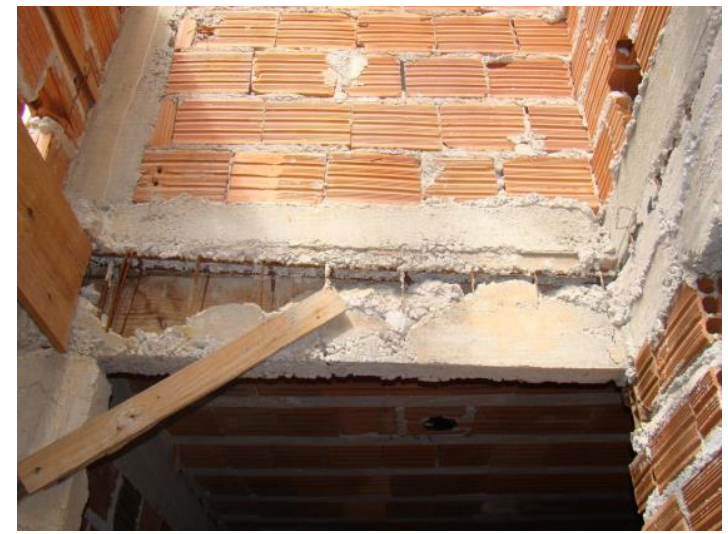

Figura 5: Nicho de concretagem em viga

\subsection{Armadura exposta}

As armaduras expostas são causadas por falhas na concretagem, espaçamento entre as barras de aço e $\mathrm{c}_{\text {nom. }}$.

Na Figura 6 observa-se a falha ao ser executada a concretagem da viga e a montagem da laje que, desamarrando os estribos da armadura para fazer o encaixe da vigota da laje, expôs a armadura, diminuindo sua função estrutural.

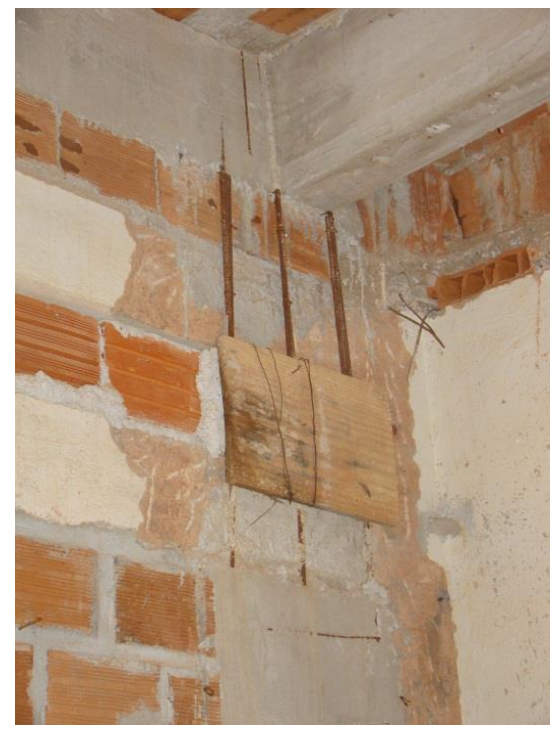

Figura 6: Armaduras expostas

Destaca-se a importância do atendimento ao $\mathrm{c}_{\text {nom }}$ discorrido no item 2.2.4, considerando que, para pilares, o $\mathrm{c}_{\text {nom }}$ deve ser de $30 \mathrm{~mm}$ e que o edifício está inserido na região urbana da cidade de Teófilo Otoni/MG, com CAA II.

Os riscos mais comuns são o surgimento de manifestações patológicas na armadura, como a corrosão do aço. Dependendo do nível ou da forma que a armadura está exposta, é necessário o reforço para que a estrutura não chegue a colapso.

\subsection{Corrosão de armaduras}

A corrosão das armaduras ocorreu quando foram expostas ao ambiente, por se encontrarem indevidamente desprotegidas. O processo de corrosão apresentou-se de forma visível, pois tinha coloração vermelho-marromacastanhado e mancharam os elementos de concreto armado.

Segundo o Instituto Brasileiro do Concreto (2015), a corrosão é a despassivação por penetração do cloreto através de processos de difusão, de impregnação ou de absorção capilar de águas contendo teores de cloreto que, ao superarem um certo limite em relação à concentração de hidroxilas na solução dos poros do concreto, em geral da ordem de $0,4 \%$ da massa de cimento Portland ou $0,05 \%$ da massa de concreto, despassivam a superfície do aço e instalam a corrosão. 
As prováveis causas são o acréscimo de aditivo à base de cloretos e outros agentes químicos, o $\mathrm{c}_{\text {nom }}$ das armaduras abaixo dos valores recomendados na Tabela 2 , concreto executado com elevada relação água/cimento, acarretando sua elevada porosidade, a segregação do concreto, bem como a disposição inadequada das formas.

Para diagnosticar a corrosão de armaduras foi necessário avaliar o estado que elas se encontravam, ocorrendo de duas maneiras:

a) superficial: armaduras expostas, mas não corroídas, ou com início de corrosão em que se forma a película de óxido (Figuras 7 e 8);

b) média: quando apresenta redução de até $20 \%$ da seção nominal da área da seção transversal da barra;

c) profunda: quando há redução de mais de $20 \%$ da seção nominal da área da seção transversal da barra.

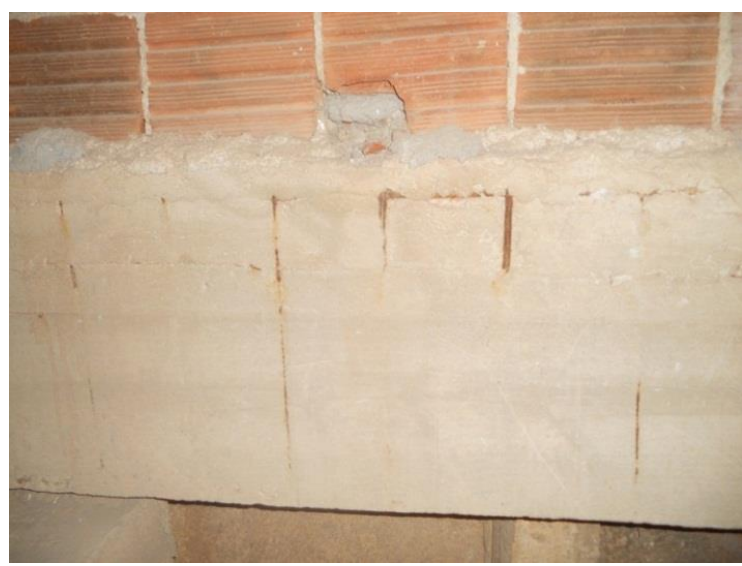

Figura 7: Corrosão superficial da armadura em viga

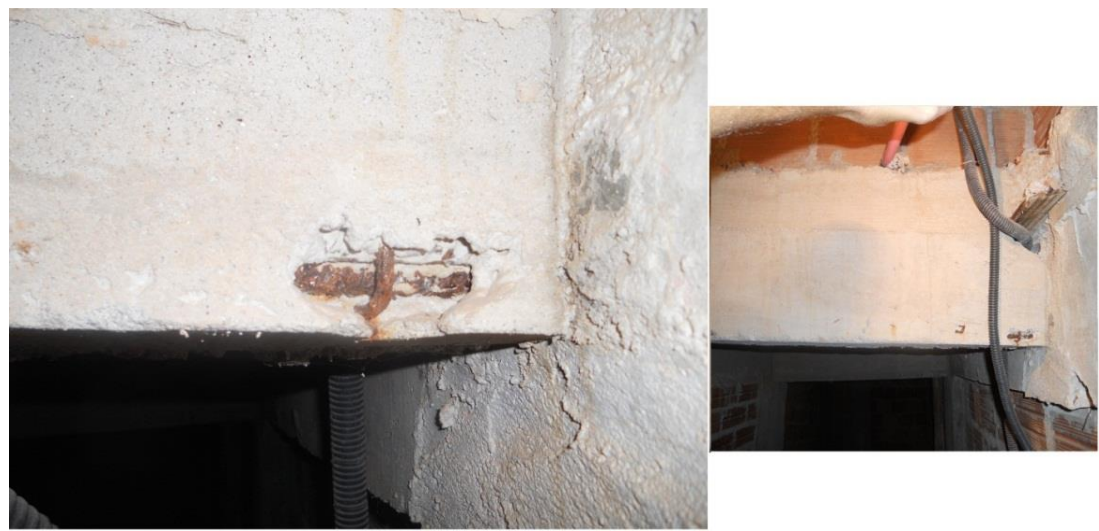

Figura 8: Corrosão superficial da armadura em viga

\subsection{Fissuras}

Conforme a NBR 6118 (ABNT, 2014), a abertura máxima característica $\left(\mathrm{w}_{\mathrm{k}}\right)$ das fissuras, desde que não exceda 0,2 $\mathrm{mm}$ a $0,4 \mathrm{~mm}$, sob ação de combinações frequentes, não tem importância significativa na corrosão das armaduras passivas, ou seja, que não sejam usadas para produzir forças de protensão, isto é, que não seja previamente alongada (ABNT, 2014).

Considerando o estado-limite de abertura das fissuras (ELS-W), os valores-limites da $\mathrm{w}_{\mathrm{k}}$ das fissuras para concreto armado (Tabela 3) visam garantir proteção adequada das armaduras quanto à corrosão. Entretanto, devido à alta variabilidade das grandezas envolvidas, esses limites devem ser vistos apenas como critérios para um projeto estrutural adequado.

Conforme a Tabela 3, os elementos de concreto armado, considerando CAA II, podem ter $w_{k} \leq 0,3 \mathrm{~mm}$, mas não se deve esperar que as $w_{k}$ de fissuras reais correspondam estritamente aos valores estimados, isto é, fissuras reais podem eventualmente ultrapassar esses limites (ABNT, 2014). 
Tabela 3 - Exigências de durabilidade relacionadas à fissuração e à proteção da armadura, em função das classes de agressividade ambiental

\begin{tabular}{|c|c|c|c|}
\hline Tipo de concreto estrutural & $\begin{array}{c}\text { Classe de agressividade ambiental } \\
\text { (CAA) }\end{array}$ & $\begin{array}{l}\text { Exigências relativas à } \\
\text { fissuração }\end{array}$ & $\begin{array}{l}\text { Combinação de ações } \\
\text { em serviço a utilizar }\end{array}$ \\
\hline \multirow{3}{*}{ Concreto armado } & CAA I & $\mathrm{w}_{\mathrm{k}} \leq 0,4 \mathrm{~mm}$ & \multirow{3}{*}{ Combinação frequente } \\
\hline & CAA II e CAA III & $\mathrm{w}_{\mathrm{k}} \leq 0,3 \mathrm{~mm}$ & \\
\hline & CAA IV & $\mathrm{w}_{\mathrm{k}} \leq 0,2 \mathrm{~mm}$ & \\
\hline
\end{tabular}

Fonte: ABNT (2014).

No edifício, as fissuras diagnosticadas estavam nas lajes (Figura 9), com $\mathrm{w}_{\mathrm{k}}>0,3 \mathrm{~mm}$, podendo ter as possíveis causas variadas, como má execução de desenforma ou escoramentos retirados antes do tempo previsto.

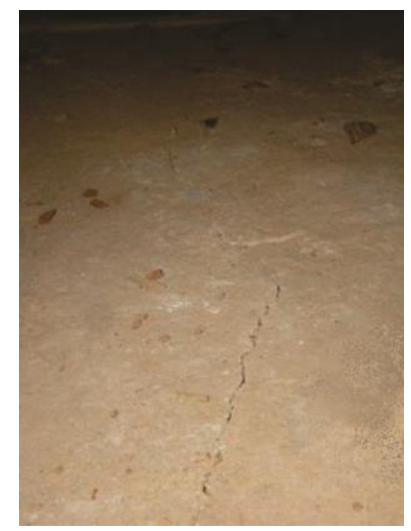

Figura 9: Fissura na laje

Para se recuperar as fissuras foi usado jato de água e areia para fazer a limpeza da região de localização das fissuras e posteriormente, a aplicação de resina à base de epóxi. Depois da aplicação da mesma, foram usadas telas para não deixar transmitir os esforços solicitantes atuantes nas lajes.

\section{CONSIDERAÇÕES FINAIS}

Esta análise aborda os problemas causados pela má execução de elementos de concreto armado, bem como informações sobre as prováveis causas do surgimento de manifestações patológicas e algumas sugestões de procedimentos de recuperação.

Constatou-se que a principal causa da deterioração desses elementos foi a ineficiência na execução, oriunda de mão de obra desqualificada, o que comprometeu a qualidade final dos serviços.

Dentre as causas destacaram-se as falhas no preparo, adensamento e lançamento do concreto, sendo indispensável o controle de qualidade deste material para minimizar os tipos de manifestações patológicas descritas.

Os programas que visam à qualidade buscam por um bom planejamento para diminuir os erros durante as etapas de execução da construção, desenvolvimento de treinamento para a mão de obra e elaboração de melhores e mais detalhados procedimentos executivos, que como resultado contribui também nos custos. É mais viável prevenir o aparecimento das falhas à recuperá-las, visto que a manutenção corretiva é considerada a fase mais onerosa da indústria da construção civil.

\section{REFERÊNCIAS}

ALEXANDER, M. G. Construindo um projeto de vida útil de estruturas de concreto - Histórico, desenvolvimentos e implementação. Revista ALCONPAT, Mérida, v. 8, n. 3, p. 224-245, set.-dez. 2018. Disponível em: file://C:/Users/Diana/Downloads/351-2620-2-PB\%20(1).pdf. Acesso em: 1 jan. 2020.

ANDRADE, C. Manual de diagnósticos de obras deterioradas por corrosão de armaduras. São Paulo: Pini, 1992. $104 \mathrm{p}$. 
ASSOCIAÇÃO BRASILEIRA DE ENGENHARIA E CONSULTORIA ESTRUTURAL. Check list para vistoria de edificações em concreto armado. São Paulo: ABECE, 2005. Acesso em:

https://site.abece.com.br/images/download/pdf/CT_ABECE_CHECKLIST_FINAL.pdf. Acesso em: 27 dez. 2019.

ASSOCIAÇÃO BRASILEIRA DE NORMAS TÉCNICAS. ABNT NBR 6118: projeto de estruturas de concreto Procedimento. Rio de Janeiro: ABNT, 2014.

. ABNT NBR 7212: execução de concreto dosado em central - Procedimento. Rio de Janeiro: ABNT, 2012.

ABNT NBR 12655: concreto de cimento Portland - Preparo, controle, recebimento e aceitação -

Procedimento. Rio de Janeiro: ABNT, 2015.

. ABNT NBR 14931: execução de estruturas de concreto - Procedimento. Rio de Janeiro: ABNT, 2004. ABNT, 2013.

ABNT NBR 15575-1: edificações habitacionais - Desempenho. Parte 1: requisitos gerais. Rio de Janeiro:

ABNT NBR 15575-2: edificações habitacionais - Desempenho. Parte 2: requisitos para os sistemas estruturais. Rio de Janeiro: ABNT, 2013.

Janeiro: ABNT, 1998.

ABNT NBR NM 67: concreto - Determinação da consistência pelo abatimento do tronco de cone. Rio de

CUPERTINO, D. Apresentação e análise dos resultados. In: CUPERTINO, D. Análise de solicitações de assistência técnica em empreendimentos residenciais como ferramentas de gestão. 2013. Dissertação (Mestrado em Engenharia Civil) - Escola de Engenharia Civil, Universidade Federal de Goiás, Goiânia, 2013. p. 89-90.

Disponível em: file:///C:/Users/Diana/Desktop/Disserta\%C3\%A7\%C3\%A3o\%20-

\%20Daniel\%20Cupertino\%20da\%20Cruz\%20-\%202013.pdf. Acesso em: 18 abr. 2019.

INSTITUTO BRASILEIRO DO CONCRETO (Brasil). ABNT NBR 6118:2014: comentários e exemplos de aplicação. São Paulo: Instituto Brasileiro do Concreto, 2015.

MARCELLI, M. Sinistros na construção civil: causas e soluções. São Paulo: Pini, 2007. 259 p.

PEDROSO, F. L. Seminário orientou profissionais quanto às boas práticas construtivas. Concreto \& Construções, São Paulo, ano 92, p. 54-55, out-dez. 2018. Disponível em:

http://ibracon.org.br/Site_revista/Concreto_Construcoes/revista-interna_92.php. Acesso em: 12 abr. 2019.

RODRIGUES, P. P. F. Parâmetros de dosagem do concreto. São Paulo: ABCP, 1998. (Estudo Técnico ET-67). Disponível em: https://www.abcp.org.br/cms/download/. Acesso em: 29 jan. 2016.

SOUZA, V. C. M. S.; RIPPER, T. Patologia, recuperação e reforço de estruturas de concreto. São Paulo: Pini, 1998. $257 \mathrm{p}$.

TUTIKIAN, B.; PACHECO, M. Inspeção, diagnóstico e prognóstico na construção civil. Mérida: ALCONPAT, 2013. (Boletim Técnico). Disponível em: https://alconpat.org.br/homepage/publicacoes/. Acesso em: 21 jun. 2014. 